\title{
Redistribution of Cytoskeletal Proteins in Mammalian Axons Disconnected from Their Cell Bodies
}

\author{
Danny F. Watson, ${ }^{1}$ Jonathan D. Glass, ${ }^{2,3}$ and John W. Griffin ${ }^{2}$ \\ 'Department of Neurology, Wayne State University School of Medicine, Detroit, Michigan 48201 and ${ }^{2}$ Department of \\ Neurology and ${ }^{3}$ Department of Pathology, Johns Hopkins University School of Medicine, Baltimore, Maryland 21287
}

\begin{abstract}
Mice of the strain C57/BL/Ola exhibit a delay of Wallerian degeneration, such that axons survive for several weeks after a nerve transection that separates the axons from the cell bodies. In this Ola strain we have examined the distribution of cytoskeletal proteins in a $5 \mathrm{~mm}$ segment of the sciatic nerve for as long as $\mathbf{2}$ weeks after proximal and distal transections that prevent entry or exit of proteins via axonal transport. By $7 \mathrm{~d}$ after transections, there was a marked accumulation of $\alpha$ - and $\beta$-tubulin, actin, and nonphosphorylated neurofilament epitopes at the proximal and at the distal ends of the transected axons, and loss of these proteins from the center of the isolated nerve segment. Highly phosphorylated neurofilament epitopes did not redistribute along the nerve, but there was a gradual loss of phosphorylated neurofilament immunoreactivity. These observations indicate the potential for bidirectional transport of a substantial portion of certain cytoskeletal proteins within axons of the PNS.
\end{abstract}

[Key words: axonal transport, cytoskeleton, Ola mouse, neurofilaments, tubulin, actin]

The process of axonal transport was initially demonstrated by injection of radioactive amino acids near neuronal cell bodies followed by analysis of the proteins in their axons many days later (Hoffman and Lasek, 1975). Since that time, studies using the same strategy have demonstrated discrete phases of transport (Willard and Hulebak, 1977; Black and Lasek, 1980) and have identified the involvement of the transport process in a variety of toxic and metabolic disorders of the nervous system (Griffin et al., 1978, 1984; Bizzi et al., 1984; Medori et al., 1985; Monaco et al., 1985; Troncoso et al., 1985). Radiolabeled transport studies have also contributed to the study of normal development (Hoffman et al., 1985a), the response to axotomy (Hoffman et al., 1983, 1985b; McQuarrie and Lasek, 1989), and the effects of aging (Komiya, 1980; McQuarrie et al., 1989).

Despite these many successes, the study of transport by metabolic pulse labeling of proteins has at least two important limitations. It has not proved possible to determine whether there is any retrograde movement of cytoskeletal proteins (analogous

\footnotetext{
Received Jan. 29, 1993; revised Apr. 13, 1993; accepted Apr. 15, 1993.

We thank Mr. Frank Nachtman for his capable technical assistance. This work was supported in part by NIH Grant P01 22849. J.D.G. is recipient of NIH Clinician Investigator Development Award NS 01577 and of a Lilly Clinician Scientist Award.

Correspondence should be addressed to Dr. Danny Watson, 6E UHC, Department of Neurology, Wayne State University School of Medicine, 4201 St. Antoine, Detroit, MI 48201.
}

Copyright (C) 1993 Society for Neuroscience $0270-6474 / 93 / 134354-07 \$ 05.00 / 0$ to retrograde fast axonal transport), since metabolic labeling is not possible at the terminals of axons. Radiolabeled transport studies have also failed to establish whether radiolabeled material in the anterograde direction represents the bulk of axonal cytoskeletal proteins or whether it is a subpopulation. Indirect evidence that the main radiolabeled wave of cytoskeletal proteins differs from the total axonal population has been presented for neurofilaments (Nixon and Logvinenko, 1986; Lewis and Nixon, 1988) and for tubulin (Watson et al., 1990; Hoffman et al., 1992). Other experiments indicate that radiolabeled transported material represents a special subpopulation of cytoskeletal proteins with regard to the spatial redistribution ("beading") induced by mechanical stretch (Ochs et al., 1989). Such findings have suggested that a portion of the axonal cytoskeleton may be stationary except for slow exchange with passing transported material. The evidence for such a model has been indirect, however, since no alternative to metabolic radiolabeling has been available for the study of slow axonal transport.

An alternative method of study was suggested by the identification of a strain of mice that exhibit prolonged survival of axons disconnected from their cell bodies (I unn et al., 1989; Perry et al., 1991). Ultrastructural studies have indicated that some degree of redistribution of the cytoskeleton appears in these surviving nerve fibers because neurofilaments accumulate at their transected ends (Glass and Griffin, 1991). We have therefore systematically evaluated the redistribution of several cytoskeletal proteins in surviving axons of the C57/BL/6/Ola mice for periods up to $13 \mathrm{~d}$. Our results indicate that there is both anterograde and retrograde redistribution of cytoskeletal proteins over distances of several millimeters. Furthermore, the amount of material involved in this redistribution appears to represent only a portion of the total axonal cytoskeleton.

\section{Materials and Methods}

Preparation of nerves. Male and female mice of the strain C57/BL/6/ Ola were obtained from the breeding colony maintained at the Johns Hopkins Hospital. All mice were aged 4 months at time of nerve transection. The procedure is schematically shown in Figure 1.

Under methoxyflurane anesthesia, the bilateral sciatic nerves were exposed and transected with iridectomy scissors at the hip and the knce. Care was taken to produce an isolated segment $5-5.5 \mathrm{~mm}$ in total length. Animals were allowed to survive for $0 \mathrm{hr}$ (nerves removed immediately), $2 \mathrm{hr}$, or $1,2,4,7$, or $13 \mathrm{~d}$. Six nerves were obtained for each survival time.

After the planned survival, animals were reanesthetized and nerves were removed and rapidly frozen at $-70^{\circ} \mathrm{C}$. Frozen nerves were placed on a plastic ruler, and subsequently divided into 10 pieces each $0.5 \mathrm{~mm}$ long by use of a microknife and dissecting microscope at $20 \times$. Each segment was then homogenized in $8 \mathrm{M}$ urea, $5 \%$ mercaptoethanol in $0.05 \mathrm{M}$ sodium phosphate buffer, $\mathrm{pH} 7.2$. In a few cases the actual nerve 


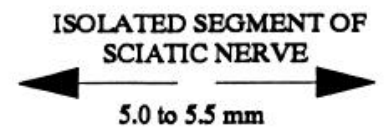

$\begin{array}{llllllllll}1 & 2 & 3 & 4 & 5 & 6 & 7 & 8 & 9 & 10\end{array}$

hip

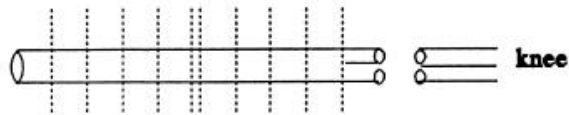

Figure 1. Experimental procedure. At time zero the sciatic nerve was transected at the hip and the knee to produce a $5 \mathrm{~mm}$ segment isolated from cell bodies and terminals. After survival times of up to $13 \mathrm{~d}$, the nerve was removed, divided into consecutive $0.5 \mathrm{~mm}$ samples, and prepared for immunoassay.

lengths at time of division into these segments slightly exceeded $5 \mathrm{~mm}$; in these cases the excess $0.1-0.6 \mathrm{~mm}$ in the center of the isolated segment was discarded.

Four nerves prepared by transection at the hip and the knee were immersion fixed in $5 \%$ glutaraldehyde in $0.1 \mathrm{~m}$ sodium phosphate buffer and embedded in plastic, two nerves each at 7 and $14 \mathrm{~d}$ of survival. Sections $1 \mu \mathrm{m}$ thick were prepared from the middle portions of these nerves and scored for the numbers of intact and degenerated axons.

Immunoassay. Immunoassay was performed exactly as described previously (Watson et al., 1989b, 1990). Mouse monoclonal antibodies to $\alpha$-tubulin and $\beta$-tubulin (Amersham) and to the $\beta \mathrm{II}$ and $\beta \mathrm{III}$ isotypes of $\beta$-tubulin (gift of Dr. Richard Luduena) were assayed separately. Additional antibodies were to NF-L (Boehringer-Mannheim) and NF-H in a conformation associated with high degrees (SMI31) or low degrees (SMI32) of phosphorylation (Sternberger-Meyer Immunochemicals) or nonmuscle actin (Sigma). Standard preparations of known tubulin or neurofilament content were assayed in parallel and the absolute amount of these proteins (in terms of equivalent standard) was computed for each segment. Because binding of the actin antibody to rat muscle actin was limited, muscle actin proved an inadequate standard for the nonmuscle actin. Data for the actin antibody therefore were analyzed only as absorbance units. All homogenates were diluted 1:30, at which the background mouse IgG content was low and the cytoskeletal proteins exhibited linear change in absorbance with change in concentration (Fig. 2).

Statistical analysis. The primary statistical analysis was selected prior to the study. It was anticipated (from morphologic data) that significant bulk redistribution of the cytoskeletal proteins might lead to accumulation in two adjacent segments. Therefore, for each nerve, for each antibody, the sum of protein contents for segments 1 and 2 (see Fig. 1) was compared to the sum of segments 4 and 5 by two-tailed $t$ test (with $n=6$ nerves per survival interval, $\mathrm{df}=10$, and level of significance of $0.05)$. Similarly the sum of segments 9 and 10 was compared to the sum of 6 and 7. These comparisons were performed at each survival interval from 0 to $13 \mathrm{~d}$. Because of the decrease in the absolute amount of neurofilament proteins NF-L and SMI31 after transection, the variances decreased with time for these proteins and analysis of variance was deemed no more appropriate than the $t$ test.

\section{Results}

\section{Morphological survival of axons}

Only rare degenerating axons were observed in the nerves at 7 $\mathrm{d}$ after transection. At $14 \mathrm{~d}$ a modest number of fibers showed degeneration ranging in appearance from slight disruption of myelin or axoplasmic structure to myelin ovoids without visible axoplasm. The two nerves analyzed showed comparable numbers of fibers in process of degeneration: 104 degenerated of 686 total in nerve 1 , and 110 degenerated of 751 total in nerve 2, or a mean of $14.9 \%$ (Fig. 3).

\section{Change in total cytoskeletal protein in an isolated segment}

The total amounts of tubulin, of the axon-specific isotypes of $\beta$-tubulin, and of actin did not change during the 2 weeks that

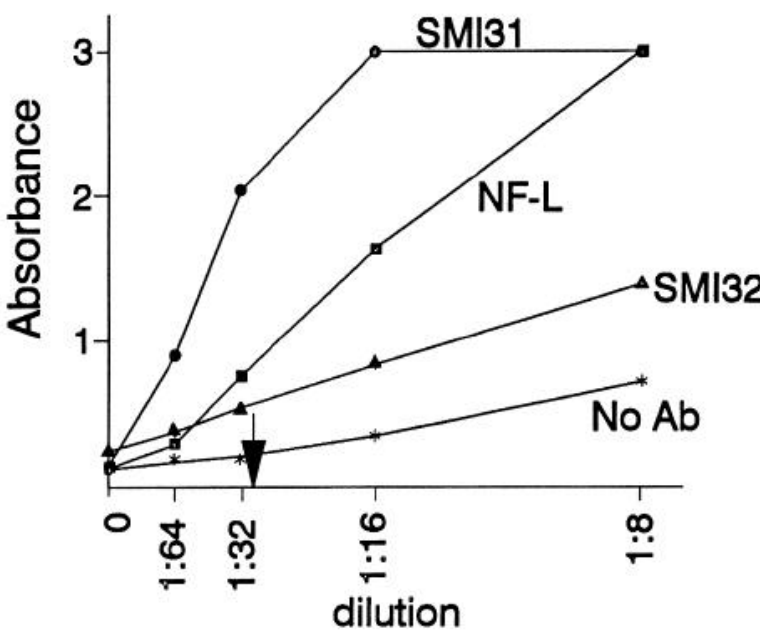

Figure 2. Selection of dilution for assay. Serial twofold dilutions of a homogenate of a freshly removed nerve were assayed with standard ELISA conditions. The line No $A b$ was reacted with $3 \%$ normal horse serum at the step when primary monoclonal antibodies to cytoskeletal proteins were added to the other wells. The background activity in this No $A b$ group likely reflects endogenous mouse immunoglobulin in the nerve. This reactivity is much less than the specific immunoreactivity for representative monoclonal antibodies directed against cytoskeletal proteins. There is approximately a linear relationship at the dilution selected for final analysis $(1: 30$; arrow $)$.

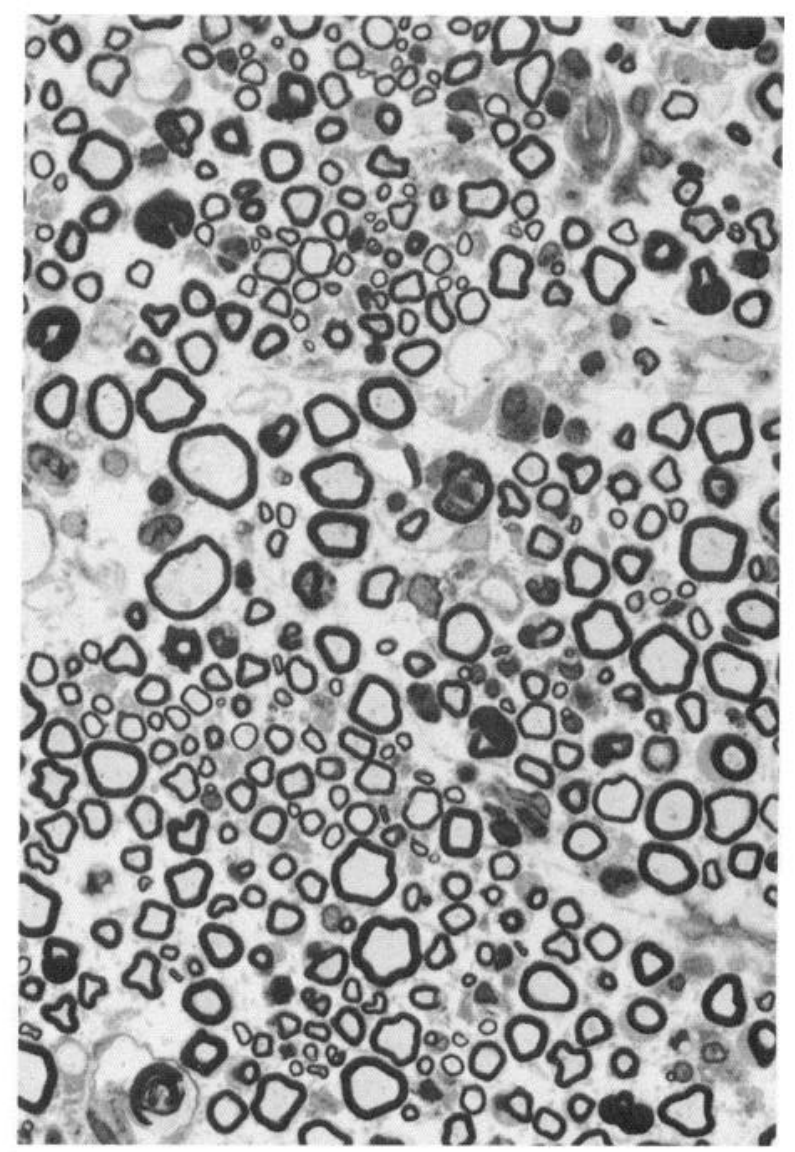

Figure 3. Representative cross-section from the midportion of the segment of a sciatic nerve transected as in Figure $114 \mathrm{~d}$ earlier. Approximately $15 \%$ of the fibers show evidence of degeneration. Plastic section of approximately $1 \mathrm{~mm}$, with toluidine blue stain. Magnification, $700 \times$. 

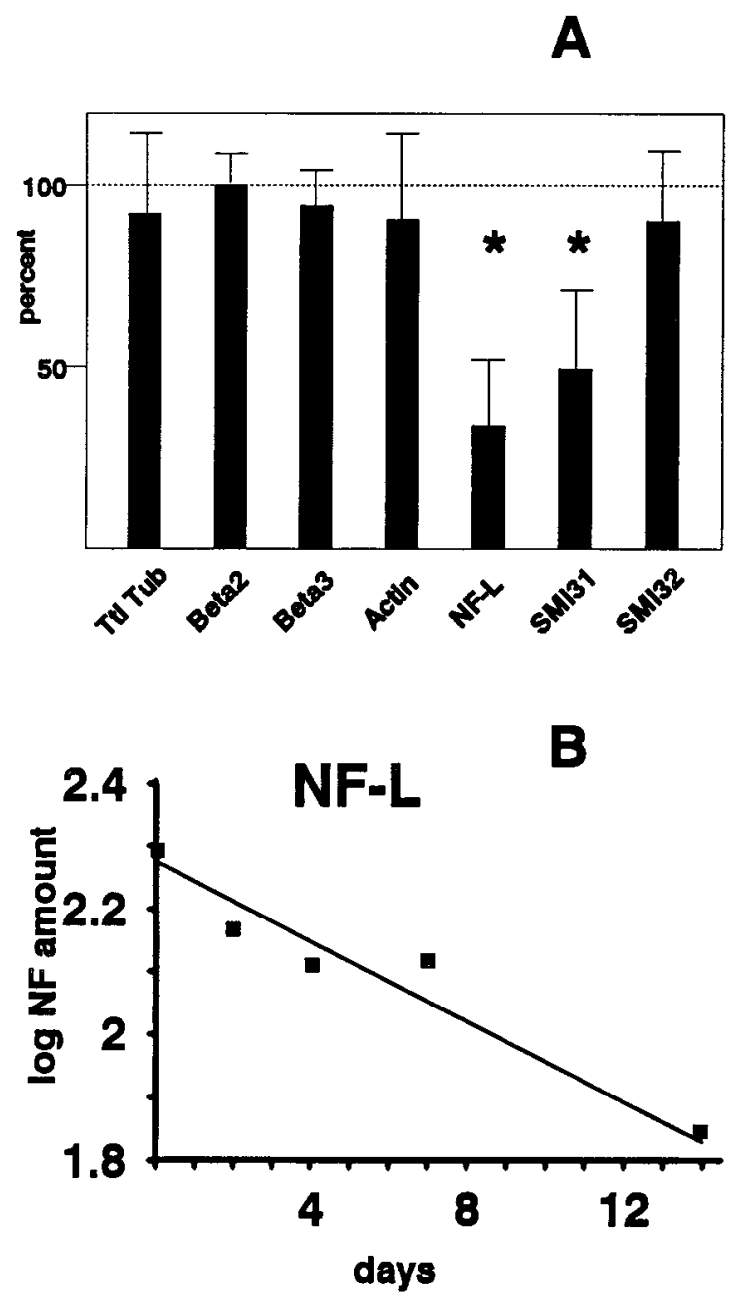

Figure 4. A. Comparison of the loss of different cytoskeletal proteins in the isolated nerve segments. The mean and SEM $(n=6)$ for the total per nerve (sum of all 10 segments) is shown as a percentage of the value immediately after transection. Tubulin, axon-specific tubulin isotypes, actin, and the population of neurofilaments bearing the nonphosphorylated SMI32 epitopes show no significant difference, although there is a trend to small decreases proportional to the structural axonal loss of $15 \%$. In contrast, total core neurofilament protein NF-L and the population of neurofilaments bearing the phosphorylated SMI31 epitope decrease to less than half the initial value $(*, p<0.05)$. $B$, Time course of loss of NF-L. The logarithm of mean content of NF-L by immunoassay, summed for all 10 samples of each nerve, is indicated as a function of time after nerve transections. The least-squares regression line is shown. The disappearance approximates a first-order process with regard to neurofilament concentration and with an apparent half-life of $9.4 \mathrm{~d}$.

the nerve remained isolated (Fig. 4). There was no significant correlation of the tubulin and actin contents with survival time ( $r=0.06$ and $r=0.034$, respectively, by Pearson productmoment correlation).

In contrast, the total amount of the core neurofilament protein NF-L (computed as the sum in all ten $0.5 \mathrm{~mm}$ samples) declined with time after transection. As illustrated (Fig. 4) the decline approximately fits a linear regression of logarithm of concentration against time after transection $(r=0.65, p<0.001$ that slope differs from zero). The apparent half-life estimated from this simple first-order kinetic model is $9.4 \mathrm{~d}$. Similar analysis for the epitopes detected by the SMI31 gave an estimated halflife of $13 \mathrm{~d}$ (the slopes of the regression lines on which these
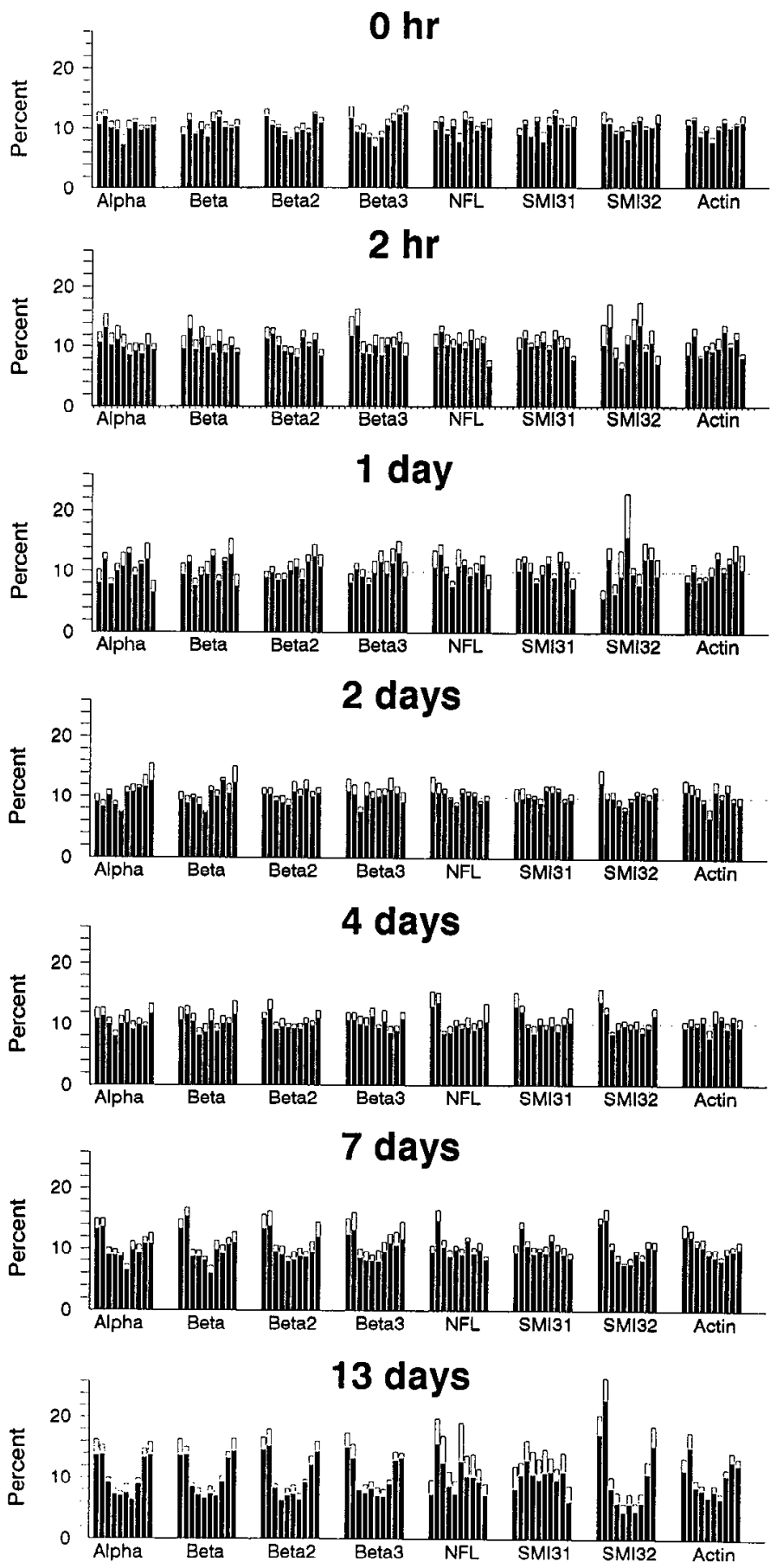

Figure 5. Redistribution of cytoskeletal proteins in the isolated nerve segment. For cach antibody, the immunoreactivity per $0.5 \mathrm{~mm}$ sample was computed as a percentage of the total, and the mean (solid bar) and $\mathrm{SE}$ (open bar) were computed for six corresponding segments. The most proximal sample (sample 1 in Fig. 1) is shown on the left. The assays differed only in the primary antibody applied to the assay wells. For nerves removed immediately after transection $(0 h r)$, the distribution of each protein was nearly uniform along the nerve. By $13 \mathrm{~d}$, accumulations of $\alpha$ - and $\beta$-tubulin, actin, and the nonphosphorylated neurofilament epitope (SMI32) was significant at the proximal and the distal cut ends of the nerve. 

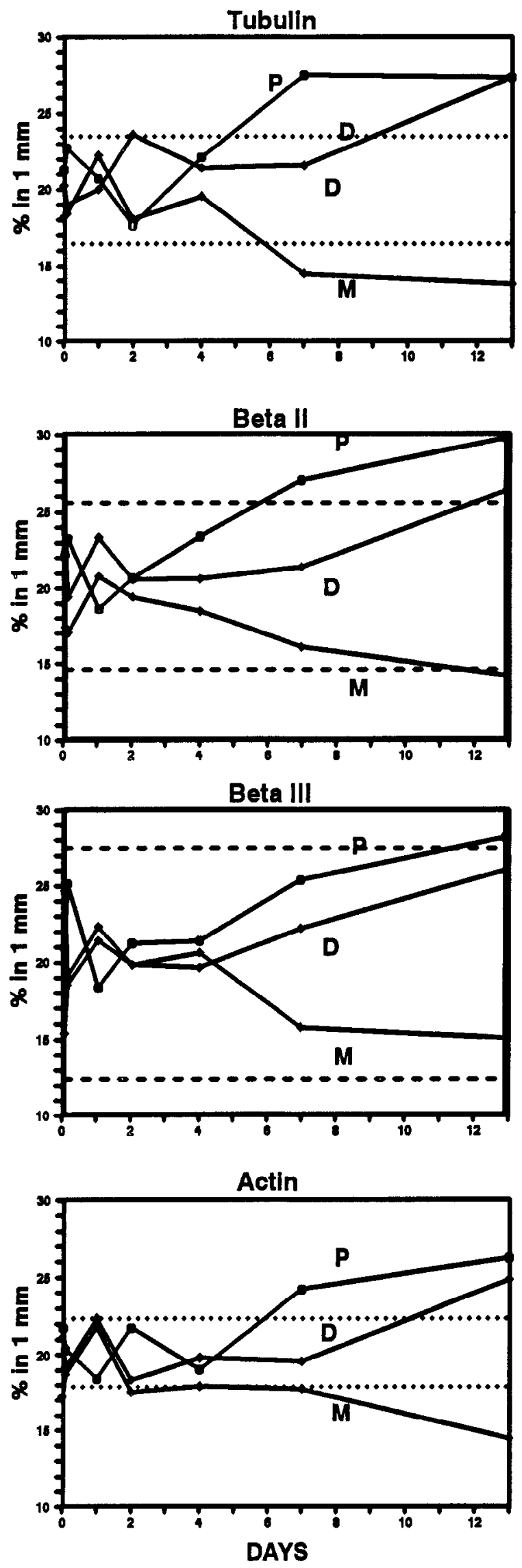

Figure 6. Time course of redistribution of tubulin and actin. The percentage of the total $\alpha-+\beta$-tubulin recovered in each nerve was computed for the $1 \mathrm{~mm}$ adiacent to each transection and for the central $1 \mathrm{~mm}$. half-lives are based do not differ significantly from each other but do differ from zero, $r=0.45$ ). The epitope on NF-H detected by antibody SMI32 did not undergo a significant decrease, reflecting either survival of a subpopulation of neurofilaments bearing this epitope or dephosphorylation of neurofilaments to produce increased binding of SMI32 to the reduced number of neurofilament subunits.

\section{Distribution of cytoskeletal proteins}

At $0 \mathrm{hr}, 2 \mathrm{hr}, 1 \mathrm{~d}$, or $2 \mathrm{~d}$, there was no significant difference in the content of the samples at the ends of the isolated nerve segment compared to the middle samples for any cytoskeletal protein (Fig. 5). By $13 \mathrm{~d}$, there was marked accumulation of several cytoskeletal proteins at the proximal and the distal ends of the isolated segment, with a corresponding reduction in the abundance in the central portion (Fig. 5). The accumulations at the transected ends were not the same for all proteins. $\alpha$ - and $\beta$-tubulin subunits and actin showed approximately equal accumulations at the proximal and distal transections. The nonphosphorylated NF-H epitope also accumulated at both ends of the isolated segment, with somewhat greater amounts at the proximal end.

In contrast, there was no significant accumulation of NF-L or of the phosphorylated NF-H epitope by the planned statistical analysis. A slight tendency to accumulate materials in segments 2 and 9 was counterbalanced by a tendency to less NF-L or SMI31 immunoreactivity in segments 1 and 10 . Because any analysis of difference between segments 1 and 2 (or 9 and 10) is post hoc and suggested by the data, it is difficult to define the statistical significance of this observation.

The development of the accumulations of tubulin subunits and actin over time is indicated in Figure 6. No clear differences in the distribution of proteins developed until $7 \mathrm{~d}$. At that time, the proximal accumulation was greater than that distal, and the decrease in the content of the middle of the isolated segment was just apparent. Between 7 and $13 \mathrm{~d}$, the distal accumulation reached a similar magnitude to that proximal and the content of the middle portion further decreased. Because there was no net change in the total amount of these proteins, the redistribution reflected an absolute increase in the amount of tubulin and actin at the cut ends of the nerves.

The pattern of the neurofilament accumulation was different from that of actin or tubulin (Fig. 7). At all times (even immediately after transection) there was a trend for a greater neurofilament content in the proximal than the distal segment, suggesting that a small gradient of neurofilament content exists along the nerve in the normal state. No similar trend was apparent for tubulin or actin. Allowing for this small difference in the starting contents, there was no evidence for accumulation of NF-L or SMI31 epitopes at the transected ends.

In contrast, the dephosphorylated NF-H epitope measured by SMI32 showed clear-cut accumulations with a time course similar to tubulin and actin. In fact, the degree of redistribution

These percentages were then indicated for each time assayed. If a protein were evenly distributed along the nerve, then a value of $20 \%$ for each segment would be expected. Broken lines indicate the $95 \%$ confidence interval for the mean of six nerves. By $13 \mathrm{~d}$, both the proximal $(P)$ and distal $(D)$ segments exhibited accumulations and the middle segment $(M)$ showed net loss of tubulin and actin. The proximal accumulation was more pronounced than the distal at day 7 . 

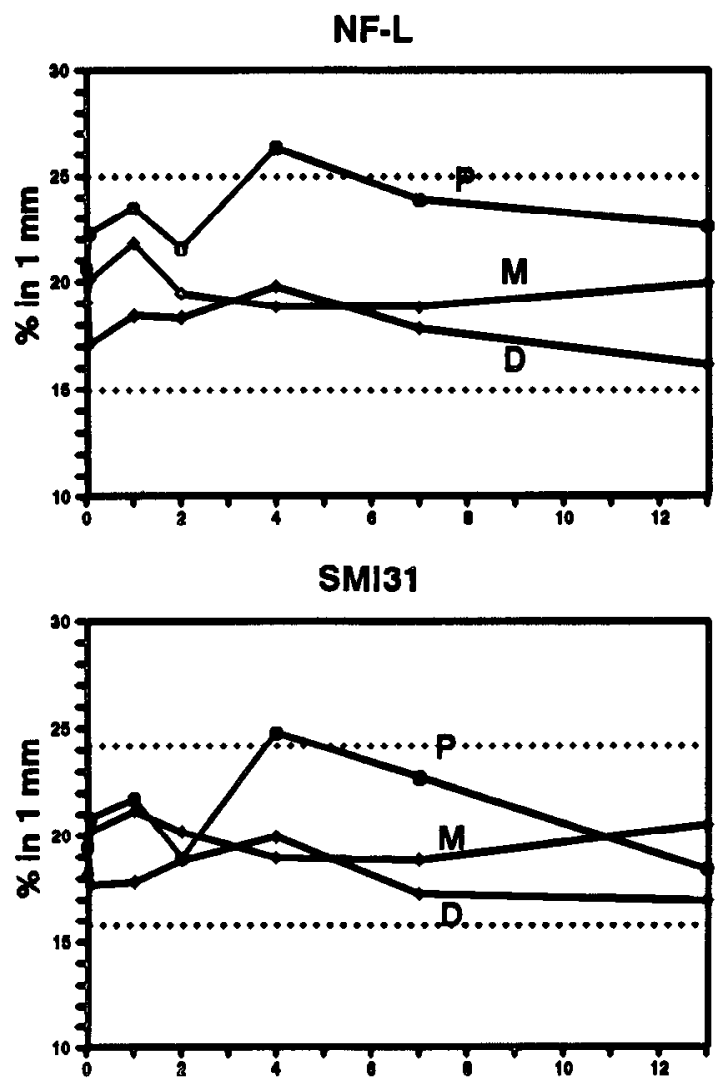

SMI32

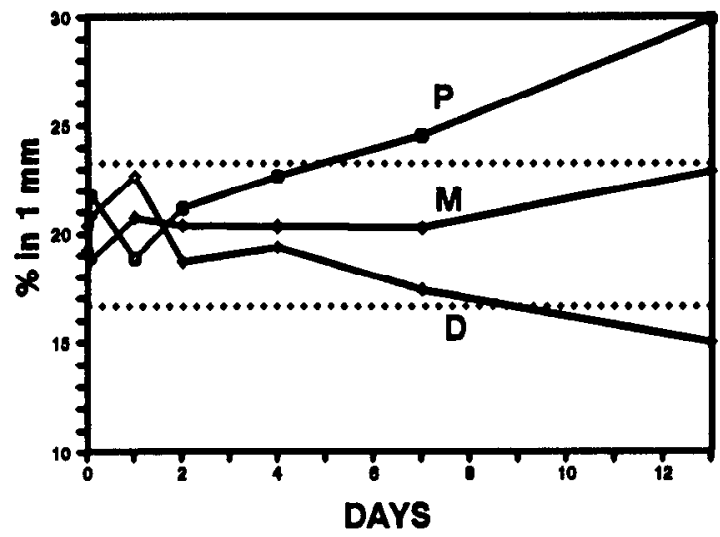

Figure 7. Time course of redistribution of neurofilament proteins. The percentage of NF-L, SMI31, or SMI32 immunoreactivity contained in the $1 \mathrm{~mm}$ adjacent to each transection or in the middle segment $(M)$ was computed. Broken lines indicate the $95 \%$ confidence interval for the mean of six nerves. For NF-L and SMI31 (phosphorylated epitope) there was an overall trend for a greater percentage in the proximal $(P)$ than the distal $(D)$ segments, but this trend did not reach statistical significance at individual time points. There was no definite redistribution of immunoreactivity with these antibodies. In contrast, the SMI32 (nonphosphorylated epitope) immunoreactivity showed a redistribution as great as tubulin and actin.

was somewhat greater for the neurofilament epitopes detected by SMI32 than for any other cytoskeletal protein.

\section{Discussion}

\section{Immunoassay compared to morphologic observations}

Morphologic studies confirmed the survival of more than $85 \%$ of the sciatic axons throughout the time studied. Previous stud- ies with the same transection paradigm indicate that substantial numbers of fibers may persist as long as $28 \mathrm{~d}$ (Glass and Griffin, 1991). The preservation of total tubulin and actin immunoreactivity throughout the 2 week interval further supports the morphologic observation that no major loss of axoplasm occurred.

The decline in total neurofilament (NF-L) content to onethird of its original value, therefore, cannot be accounted for by simple loss of axons. The observation of decline in NF-L suggests instead proteolysis (Schlaepfer et al., 1985) within surviving axons. (There is no evidence to date for the formal alternative of exocytosis of neurofilaments from axons.) The other assayed proteins that are specifically intra-axonal, namely, $\beta \mathrm{II}$ and $\beta \mathrm{III}$ tubulin, did not decline. Hence, proteolysis within the axoplasm exhibits a degree of selectivity for neurofilament subunits.

The observed slow loss of neurofilaments with a half-life of many days might be a phenomenon restricted to the injured axonal segments. The loss of neurofilaments was not an abrupt event restricted to the hours or first days after injury; nonetheless, neurofilament loss may have been induced or accelerated by injury or by loss of regulatory influences from the cell bodies or axon terminals. Alternatively, the loss of neurofilaments in these disconnected axons might reflect a process that occurs normally in axons but that is usually counterbalanced by delivery of neurofilaments from the cell bodies. Studies of the net slowing of radiolabeled transport of neurofilaments as they advance along the rat sciatic nerve have suggested that one means of maintaining stable axonal dimension might be proteolysis of small numbers of neurofilaments (Watson et al., 1989a); however, the theoretical estimate of the amount proteolyzed was less than $2 \%$ per day, compared to the rates over $5 \%$ per day observed in the isolated segments.

Previous investigations have shown axonal swelling in a proportion of the axons adjacent to the transections, and have indicated that both proximal and distal swellings occur (Glass and Griffin, 1991). The same studies showed atrophy of axons in regions adjacent to the swellings. Those studies could not fully address whether the region of axoplasmic accumulation occurred over a portion of an internode or over longer distances. The present results clearly indicate that there is major redistribution of cytoskeletal proteins over a distance of $2.5 \mathrm{~mm}$. The studies of Glass and Griffin (1991) indicated that neurofilaments were one component of the axonal swellings, but the net balance of tubulin and actin could not be directly assessed. The present results indicate that the redistribution involves neurofilament subunits, tubulins, and actin, the major components of all three abundant cytoskeletal structures in the axon.

\section{Bulk redistribution in the isolated segment and radiolabeled transport}

The rate of distal accumulation of actin, tubulin, and dephosphorylated neurofilament epitopes was less than expected from the velocity of radiolabeled transport. Recent studies of the rate of slow axonal transport in the midportion of the mouse sciatic nerve have indicated a rate of neurofilament transport approximately $0.7 \mathrm{~mm} / \mathrm{d}$ and a rate of actin and tubulin transport approximately $1.5 \mathrm{~mm} / \mathrm{d}$ (de Waegh and Brady, 1991; de Waegh et al., 1992). If radiolabeled protein transport reflected net anterograde movement of the bulk of cytoskeletal proteins, and if this process continued after nerve transection, then significant distal accumulation and proximal loss would be expected by 
day 2 after transection. In fact, distal accumulations were small even at day 7 and did not become substantial until day 13 .

The second major finding not predicted by studies of radiolabeled transport is the accumulation of proteins at the proximal transection, that is, cytoskeletal protein transport in the retrograde direction. One prior report of labeled transport after local covalent protein labeling identified some material moving as an apparent retrograde slow phase of axonal transport (Mata et al., 1985). That work has been difficult to interpret since movement of labeled materials in the endoneurial space rather than within axons was not definitely excluded. In the present studies, the presence of morphologic axonal swellings and the transport of neurofilament proteins (at least for the nonphosphorylated form) and axon-specific isotypes of tubulin strongly implicate intraaxonal retrograde transport and not endoneurial transport. Prcliminary studies (J. D. Glass and J. W. Griffin, unpublished observations) of radiolabeled neurofilaments and tubulin after transection of the sciatic in Ola mice further confirm the intraaxonal nature of the redistribution process.

The observed phenomenon of retrograde cytoskeletal transport may be a special case in response to injury of the isolated axons. Alternatively, it may reflect a process that goes on normally to some degree but that has been difficult to demonstrate directly with radioactive metabolic labeling paradigms. The slowing and broadening of radiolabeled transport waves along the course of nerves (Watson et al., 1989a) could be compatible with bidirectional transport of individual cytoskeletal polymers. The net transport rates would then be a reflection of the net displacement by transport in the anterograde minus displacement in the retrograde direction. Retrograde transport apparently is not restricted to the double transection model; similar axonal swellings occur in Ola nerves that have been singly transected (Glass and Griffin, 1991).

\section{Differential redistribution of neuroflaments}

A proximal-to-distal decrease in content of neurofilament immunoreactivity along the course of the rodent sciatic nerve has previously been reported (Schlaepfer and Bruce, 1990). The present results, over a smaller region of the sciatic, show a trend consistent with that report.

The difference in redistribution of the different neurofilament subunits assayed is strongly suggestive of different pools of neurofilament proteins in the axon with different properties in regard to the redistribution process. The SMI32 epitope is relatively scarce in nerve trunks of the rodent PNS (Pestronk et al., 1990; Watson et al., 1991), where the degree of phosphorylation of neurofilaments is high. Hence, it is likely that SMI32 detects only some subpopulation of neurofilaments. The marked redistribution of this epitope suggests that it is associated with neurofilaments that move with a greater net velocity than the heavily phosphorylated neurofilament subunits. A similar correlation of phosphorylation and net rate of transport has previously been observed in several axonal systems (Lewis and Nixon, 1988; Watson et al., 1989b, 1991). It is not known, and the present studies do not indicate, whether there may be also be dephosphorylation of neurofilaments after they come to reside in axoplasm near the transections.

The Ola axons were selected because one aspect of their biology differs from their parent strain, namely, the prolonged survival after axonal transection. It seems unlikely, however, that cytoskeletal transport is organized in such a radically different way in this strain that a retrograde cytoskeletal transport phase appears de novo, given the normal development and ultrastructure of the PNS in this strain. The present model indicates at least the potential for redistribution of cytoskeletal polymers in both the anterograde and the retrograde direction. This process ultimately affects a large proportion of the total tubulin, actin, and nonphosphorylated neurofilament epitopes within the nerve. The relationship of this redistribution after injury to cytoskeletal transport in intact axons remains to be defined.

\section{References}

Bizzi A, Crane RC, Autilio-Gambetti L, Gambetti P (1984) Aluminum effect on slow axonal transport: a novel impairment of neurofilament transport. J Neurosci 4:722-731.

Black MM, Lasek RJ (1980) Slow components of axonal transport: two cytoskeletal networks. J Cell Biol 86:616-623.

de Waegh SM, Brady ST (1991) Local control of axonal properties by Schwann cells: neurofilaments and axonal transport in homologous and heterologous nerve grafts. J Neurosci Res 30:201-212.

de Waegh SM, Lee VMY, Brady ST (1992) Local modulation of neurofilament phosphorylation, axonal caliber, and slow axonal transport by myelinating Schwann cells. Cell 68:451-463.

Glass JD, Griffin JW (1991) Neurofilament redistribution in transected nerves: evidence for bidirectional transport of neurofilaments. J Neurosci 11:3146-3154.

Griffin JW, Hoffman PN, Clark AW, Carroll PT, Price DL (1978) Slow axonal transport of neurofilament proteins: impairment by beta,beta' iminodipropionitrile administration. Science 202:633-635.

Griffin JW, Anthony DC, Fahnestock KE, Hoffman PN, Graham DG (1984) 3,4-Dimethyl-2,5-hexanedione impairs the axonal transport of neurofilament proteins. J Neurosci 4:1516-1526.

Hoffman PN, Lasek RJ (1975) The slow component of axonal transport: identification of the major structural polypeptides of the axon and their generality among mammalian neurons. J Cell Biol 66:351366.

Hoffman PN, Lasek RJ, Griffin JW, Price DL (1983) Slowing of the axonal transport of neurofilament proteins during development. $\mathrm{J}$ Neurosci 3:1694-1700.

Hoffman PN, Griffin JW, Gold BG, Price DL (1985a) Slowing of neurofilament transport and the radial growth of developing nerve fibers. J Neurosci 5:2920-2929.

Hoffman PN, Thompson GW, Griffin JW, Price DL (1985b) Changes in neurofilament transport coincide temporally with alterations in the caliber of axons in regenerating motor fibers. J Cell Biol 101:13321340.

Hoffman PN, Lopata MA, Watson DF, Luduena RF (1992) Axonal transport of class II and class III $\beta$-tubulin: evidence that the slow component wave represents the movement of only a small fraction of the tubulin in mature motor axons. J Cell Biol 119:595-604.

Komiya Y (1980) Slowing with age of the rate of slow axonal flow in bifurcating axons of rat dorsal root ganglion cells. Brain Res 183:477480.

Lewis SE, Nixon RA (1988) Multiple phosphorylated variants of the high molecular mass subunit of neurofilaments in axons of retinal cell neurons: characterization and evidence for their differential association with stationary and moving neurofilaments. J Cell Biol 107:26892702.

Lunn ER, Perry VH, Brown MC, Rosen H, Gordon S (1989) Absence of Wallerian degeneration does not hinder regeneration in peripheral nerve. Eur J Neurosci 1:27-33.

Mata M, Staple J, Fink DJ (1985) Ultrastructural localization of slow retrograde axonal transport: an autoradiographic study. J Neurosci 5:2900-2908.

McQuarrie IG, Lasek RJ (1989) Transport of cytoskeletal elements from parent axons into regenerating daughter axons. J Neurosci 9:436446.

McQuarrie IG, Brady ST, Lasek RJ (1989) Retardation in the slow axonal transport of cytoskeletal elements during maturation and aging. Neurobiol Aging 10:359-365.

Medori R, Autilio-Gambetti L, Gambetti P (1985) Experimental diabetic neuropathy: impairment of slow transport with changes in axon cross-sectional area. Proc Natl Acad Sci USA 82:7716-7720.

Monaco S, Autilio-Gambetti L, Zabel D, Gambetti P (1985) Giant 
axonal neuropathy: acceleration of neurofilament transport in optic axons. Proc Natl Acad Sci USA 82:920-924.

Nixon RA, Logvinenko KB (1986) Multiple fates of newly synthesized neurofilament proteins: evidence for a stationary neurofilament network distributed nonuniformly along axons of retinal ganglion cell neurons. J Cell Biol 102:647-659.

Ochs S, Jersild RA Jr, Li JM (1989) Slow transport of freely movable cytoskeletal components shown by beading partition of nerve fibers in the cat. Neuroscience 33:421-430.

Perry VH, Brown MC, Lunn ER (1991) Very slow retrograde and Wallerian degeneration in the CNS of C57BL/Ola mice. Eur J Neurosci 3:102-105.

Pestronk A, Watson DF, Yuan CM (1990) Neurofilament phosphorylation in peripheral nerve-changes with axonal length and growth state. J Neurochem 54:977-982.

Schlaepfer WW, Bruce J (1990) Neurofilament proteins are distributed in a diminishing proximodistal gradient along rat sciatic nerve. $\mathrm{J}$ Neurochem 55:453-460.

Schlacpfer WW, Bruce J, Zimmerman UJ (1985) An immunoblot study of neurofilament degradation in situ and during calcium-activated proteolysis. J Neurochem 44:502-509.
Troncoso JC, Hoffman PN, Griffin JW, Hess Kozlow KM, Price DL (1985) Aluminum intoxication: a disorder of neurofilament transport in motor neurons. Brain Res 342:172-175.

Watson DF, Hoffman PN, Fittro KP, Griffin JW (1989a) Neurofilament and tubulin transport slows along the course of mature motor axons. Brain Res 477:225-232.

Watson DF, Fittro KP, Griffin JW, Hoffman PN (1989b) Phosphorylation-dependent immunoreactivity of neurofilaments increases during axonal maturation and IDPN intoxication. J Neurochem 53:18181829.

Watson DF, Hoffman PN, Griffin JW (1990) The cold stability of microtubules increases during axonal maturation. J Neurosci 10:3344 3352.

Watson DF, Fittro KP, Hoffman PN, Griffin JW (1991) Phosphorylation-related immunoreactivity and the rate of transport of neurofilaments in chronic 2,5-hexanedione intoxication. Brain Res 539: 103-109.

Willard MB, Hulebak KL (1977) The intra-axonal transport of polypcptide H: cvidence for a fifth (very slow) group of transported proteins in the retinal ganglion cells of the rabbit. Brain Res 136:289306. 